\title{
Экономика
}

\author{
УДК 336.64
}

\section{Р.О. Восканян}

\section{СЦЕНАРИИ ВЫХОДА ИНВЕСТОРА ИЗ ВЕНЧУРНЫХ ИНВЕСТИЦИЙ}

Предметом настоящего исследования выступают контрактные отношения между инвестором и основателями молодой компании, предопределяющие сценарии выхода инвестора на разных этапах развития компании.

В целях выявления основных сценариев выхода инвестора из венчурных инвестиций автором используются такие методы исследования, как синтез и сравнительный анализ. Анализ российской и зарубежной научной литературы позволил выявить, что основной акцент поставлен на выход венчурного инвестора из бизнеса, и недостаточное внимание уделяется выходу бизнес-ангела. Рассмотрены нераспространённые в России, однако используемые на практике в зарубежных странах дополнительные условия контракта, регулирующие выход инвестора из бизнеса, а именно - «drag-along», «tag along» и «demand right». Определены преимущества и недостатки основных сценариев выхода инвестора из бизнеса для обеих сторон инвестиционных отношений.

По итогам рассмотрения основных сценариев выхода инвестора из бизнеса и характеризующих их ключевые риски определен инструмент внутреннего хеджирования от риска кардинального изменения стратегии развития компании в связи со сменой инвестора - мультиголосующие акции.

Полученные в рамках исследования результаты можно использовать при формировании инвестиционных контрактов на ранних этапах развития компании.

Ключевые слова: бизнес-ангел, венчурный инвестор, венчурный контракт, теория контрактов, инвестиционный договор, миноритарий, мажоритарий, старт-ап.

DOI: $10.35634 / 2412-9593-2021-31-1-5-11$

Оптимизация источников финансирования бизнеса является одной из первоочередных задач руководства компании на любом этапе развития. Вне зависимости от возраста компании и стадии жизненного цикла остается существенным вопрос эффективности инвестиций в бизнес, подразумевающий не только своевременную продажу бизнеса, но и создание стимулов для его развития, с использованием всего арсенала финансовых и правовых инструментов современного финансового рынка.

В случае крупных компаний, прошедших процедуру размещения акций на фондовой бирже, проблема выхода инвестора из бизнеса в основном связана с риском недружественного поглощения и потери стоимости в случае, если выход инвесторов принимает массовый характер. Иную значимость данная проблема приобретает для компаний на раннем этапе развития или на этапе роста, когда собственный капитал формируется за счёт привлекаемых со стороны бизнес-ангелов, венчурных инвесторов и краудинвестинга. Перечисленные источники финансовых ресурсов являются внешними и основатели компании ограничены в способах оказания на них давления сверх прописанного в инвестиционном договоре. Для перечисленных финансовых агентов процесс инвестиций в компанию представляет инвестиционный проект с определённым сроком реализации, по окончанию которого долю в собственном капитале компании следует продать по рыночной цене. Срок реализации инвестиций может быть прописан в инвестиционном договоре, а может наступать при выполнении определённых условий (формирование стабильной чистой прибыли на протяжении трёх лет, самоокупаемость на протяжении последних пяти лет и т.п.). В момент времени, когда основатель компании продаёт долю внешним игрокам финансового рынка, формируется дополнительный риск для молодых компаний, а именно - риск потери контроля над стратегическим развитием компании.

Стратегически важной данная проблема является для высокотехнологичных компаний. Компьютеризация, формируемая на ее основе инновационная и цифровая экономика, предопределили значимую роль сектора высоких технологий в современных экономических отношениях. Большинство бизнес-ангелов и венчурных инвесторов предпочитают данный сектор экономики как наиболее перспективный и быстрорастущий. В силу того, что производственные процессы в секторе высоких технологий связаны с первоначальной продолжительной работой в области исследований и разработок, то для высокотехнологичных компаний жизненно важно грамотно разработать долгосрочную 
стратегию развития и следовать ей, подвергая минимальным корректировкам. Это обусловлено наличием эффекта масштабируемости технологий либо сервисов, который возможно реализовать только при реализации проекта полностью. Сегодня наиболее популярными являются проекты в области создания экосистем, финтеха, сервисов цифровой экономики и т.п.

Бизнес-ангел в силу специфики данного вида деятельности принимает активное участие в развитии компании и нередко подходит к процессу выхода из бизнеса с максимальной деликатностью по отношению к основателям и разработчикам бизнес-идеи. Венчурные инвесторы выполняют роль наёмных работников. Привлечённые посредством краудинвестинга инвестиции весьма похожи на привлечённые посредством фондовой биржи, поэтому стратегии выхода из бизнеса максимально отвечают их экономическим интересам. Это отчасти обуславливает зарубежный подход к исследованию стратегий выхода из бизнеса, поскольку в иностранной литературе выход инвестора из незрелого бизнеса рассматривается с двух сторон. С одной стороны, выход, то есть продажа доли бизнеса во владение, основателей, вложившихся в уставный капитал компании. С другой стороны, выход инвесторов в собственный капитал на более поздних стадиях (внешних инвесторов), которые вкладываются в уставный капитал с целью извлечения требуемой доходности в заранее определенный временной период.

В рамках настоящей работы предполагается исследовать стратегии выхода внешних инвесторов из бизнеса на ранних стадиях развития с целью поиска инструмента хеджирования от риска потери контроля над стратегическим развитием компании.

Исследование российской и зарубежной литературы позволило прийти к выводу, что большинство научных работ посвящено договорной основе отношений основателей и венчурных инвесторов. Отчасти это обусловлено тем, что венчурные инвесторы раскрывают информацию об осуществляемых сделках и тем самым формируют собственную деловую репутацию. Распространена практика, когда венчурный инвестор по завершению работы с венчурным фондом и формированию опыта и деловых связей в конкретном секторе экономике становится бизнес-ангелом. Поскольку бизнесангелы являются частными лицами и не раскрывают информацию о своей деятельности, то конкретные условия входа и выхода из бизнеса данного вида инвестора практически не доступны. Следует обратить внимание, что бизнес-ангелы инвестируют собственные денежные средства, которые в сравнении с привлекаемыми объёмами от венчурных фондов или краудинвестинга весьма скромны. Более того, в условиях ограниченности финансовых ресурсов большинство экономических субъектов совершают финансовые операции не тогда, когда для этого существует подходящий момент с точки зрения рыночной ситуации, а тогда, когда у них есть свободные деньги [1]. В этой связи представляется справедливым замечание, что цель бизнес-ангела заключается в самом выходе из бизнеса и успешность данного процесса зависит исключительно от корректного составления первоначального инвестиционного договора [2].

Один из наиболее значимых вкладов в исследование особенностей договорных отношений внёс О. Харт. Вопросы непонимания между инвесторами и основателями, менеджерами, среди прочих рассматриваются в работе учёного, посвящённой неполным контрактам и контролю [3]. В рамках исследований, посвящённых вопросам теории контрактов, нобелевский лауреат в том числе рассматривает проблемы, связанные с балансом уровня контроля и вовлечения инвестора в деятельность компании и возможностями менеджеров принимать решения, исходя из собственного профессионального суждения.

Данный вопрос также рассматривается в работе С. Каплана и П. Стрёмберга, посвящённой договорам о венчурном финансировании [4]. В исследовании подчёркивается, что основным компонентом подобных договоров является вопрос распределения контрольных прав между основателями и инвестором. Венчурные инвесторы могут принять на себя управление компанией в случае неэффективного финансового менеджмента и, наоборот, при эффективной деятельности венчурные инвесторы отказываются от большей части контроля, сохраняя право на долю в денежном потоке.

Эффективность подобной политики стала предметом мета-анализа, в рамках которого выявлено, что компании с привлечением венчурного капитала более эффективны, чем компании, привлекающие иные источники финансирования. Автор анализа обращает внимание, что это зависит исключительно от опыта венчурного инвестора, его способности формировать стоимость бизнеса и качества разработанной бизнес-модели [5]. 
В этой связи представляется значимым исследование трансформации договоров о венчурном финансировании в зависимости от так называемого «раунда» финансирования. Договор меняется от раунда к раунду в зависимости от изменения долговой нагрузки компании и включению новых венчурных инвесторов в процесс инвестирования. В данном случае срабатывает принцип, по которому более старшие инвесторы обладают большими возможностями, нежели инвесторы, подключившиеся к проекту на более поздних этапах (раундах) [6]. Это позволяет заключить, что наиболее выгодные условия выхода инвестора из бизнеса предлагаются в первом раунде и постепенно условия становятся жёстче при развитии компании и наступлении иных раундов.

Зачастую в инвестиционных договорах не указывается конкретная дата выхода инвестора из бизнеса. У компаний разных секторов экономики совершенно разные сроки выхода на окупаемость и чистую прибыль, поэтому устанавливать конкретный срок нецелесообразно. Исследование европейской практики заключения венчурных договоров выявило, что не существует высокой корреляции между временем выхода инвестора из бизнеса и выбираемой стратегии выхода. Особенно это заметно на примере высокотехнологичных компаний, характеризующихся высокой асимметрией информации и разной скоростью снижения влияния фактора неопределённости на их деятельность [7].

В настоящее время наибольшее распространение получили следующие три сценария выхода инвестора из бизнеса: продажа доли в бизнесе в обмен на денежное вознаграждение, продажа доли в бизнесе в рамках сделки слияния и поглощения и выход на фондовую биржу с первым публичным предложением акций компании (IPO).

Продажа доли в бизнесе в обмен на денежное вознаграждение может рассматриваться как самый простой сценарий выхода из бизнеса. Данный сценарий следует разделить на два: продажа доли инвестора в бизнесе и продажа всего бизнеса.

В первом случае, когда инвестор продаёт только свою долю и она является миноритарной, то зависимость бизнеса от основателей неизменна и это приводит к снижению конфликта интересов. Однако в качестве недостатка данного сценария отмечается, что продающему свою долю инвестору будет сложнее получить премию за контроль, так как для её получения требуется полная продажа компании или её поглощение покупателем [8]. Во втором случае, когда у инвестора мажоритарная доля и он продаёт бизнес целиком, то основатели могут потерять управление компанией.

В зависимости от условий инвестиционного договора, выходящий инвестор может предложить свою долю основателям, иным действующим инвесторам или же сторонним физическим и юридическим лицам. Продажа доли в бизнесе в обмен на денежное вознаграждение представляется простым сценарием ещё и по той причине, что не связана с каким-либо этапом развития компании и может быть осуществлена в любой момент времени. Подтверждением вышесказанного может выступать исследование ряда компаний американского и европейского рынков венчурного инвестирования. В рамках данной работы выявлено, что продажа бизнеса является наиболее предпочтительным сценарием выхода для инвестора, несмотря на то, что процедура IPO могла бы обеспечить венчурному инвестору значительные репутационные преимущества [9]. Португальские учёные объясняют это высоким уровнем развития деловой связи европейских венчурных инвесторов и банков, позволяющей в кратчайшие сроки решать задачу нахождения потенциального покупателя бизнеса [10].

Предполагающий выход инвестора из бизнеса в обмен на денежное вознаграждение инвестиционный договор может содержать условия, которые защищают инвестора от риска невозможности осуществления сделки в связи с наличием противоречий с иными инвесторами-совладельцами по условиям сделки.

В зарубежной практике распространено такое условие договора о выходе венчурного инвестора из бизнеса, как «drag-along» (дословно - право перетаскивания). Под данным условием понимается право мажоритарного акционера требовать от миноритарного присоединиться к сделке по продаже акций по той же цене и на тех же условиях. Данное условие защищает интересы мажоритариев и включается в договор, чтобы доказать, что миноритарии не смогут сорвать сделку по купле-продаже компании. Данное право можно рассматривать как опцион на продажу, когда согласованная внешними участниками сделки цена одной акции используется как цена исполнения опциона. Исследование работ российских учёных позволило прийти к выводу, что в действующее российское законодательство допускает использование права требования совместной продажи доли, однако широкого распространения данная практика не получила $[11 ; 12]$. 
Обратным рассмотренному условию является «tag along»- право последовать за мажоритарием при продаже им своей доли. Оно позволяет миноритарию присоединиться к сделке и продать свою долю на тех же условиях, что и мажоритарий. Приобретатель доли мажоритария обязан приобрести на тех же условиях и долю миноритария. Это может стать причиной отказа покупателя от сделки при условии, что он не обладает достаточными финансовыми ресурсами для осуществления сделки или же при условии, что у него нет необходимости в предлагаемой и мажоритарием, и миноритариями доли в бизнесе. Однако в большинстве случаев данное условие позволяет миноритариям обеспечить ликвидность своих активов.

Иллюстрацией выступает соглашение о варранте между Monaco Coach Corporation, Kay Toolson (акционер - физическое лицо), Ableco Holding LLC. Согласно данному соглашению, право «tag along» можно было использовать лишь в определённый период времени. Также присутствовала оговорка, что, несмотря на условия инвестиционного договора, акционер не имеет право осуществлять продажу, переуступку или передачу иным образом обыкновенных акции компании в объёме больше, чем 50 \% обыкновенных акций, которыми владеет акционер на дату заключения соглашения [13]. Таким образом, предоставляемые дополнительные возможности для миноритария могут иметь ограничения по времени, как и мажоритарий может быть органичен объёмом продаваемых акций.

Также существует дополнительное условие инвестиционного договора, защищающее права действующих инвесторов и позволяющее сохранить контроль над бизнесом при выходе одного из них. «Pre-emption right» (дословно - преимущественное право) требует от продающего первоначально предложить продаваемую долю иным инвесторам компании по справедливой цене, то есть по цене, которую предложил бы сторонний инвестор. Также данное условие действует при изменении уставного капитала компании, когда новые доли первоначально предлагаются действующим инвесторам для сохранения контроля перед появлением новых инвесторов в бизнесе. Возможно обращение к данному условию и в случае, если продажа доли стороннему инвестору предполагает изменение стратегии развития бизнеса и, по мнению действующих инвесторов, будет мешать формированию стоимости. В этом случае преимущественное право позволяет не только повысить контроль, но и предотвратить потенциальное снижение эффективности деятельности бизнеса.

Практика использования «pre-emption right» в Великобритании наблюдается с конца XIX в., однако лишь в 2020 г. сформировалась практика нивелирования данного дополнительного условия инвестиционного договора. В государстве существует организация «Pre-emption group», которая публикует руководства по его использованию [14]. Организация приняла решение о предоставлении дополнительной гибкости для компаний, зарегистрированных в Великобритании, из-за связанных с пандемией COVID-19 экономических сложностей. Таким образом, до 30 ноября 2020 г. компаниям предоставлялась возможность осуществить дополнительную эмиссию в объёме $20 \%$ от акционерного капитала для привлечения финансирования без первоначального предложения о покупке данных акций действующим акционерам. Данной кратковременной возможностью воспользовались такие крупные корпорации, как SSP Group (привлекшая порядка 216 млн британских фунтов стерлингов), Ten Entertainment Group (5 млн британских фунтов стерлингов) и Hotel Chocolat (20 млн британских фунтов стерлингов).

Продажа доли в бизнесе в рамках сделки слияния и поглощения представляет собой второй сценарий выхода инвестора из бизнеса. В сравнении с IPO, сделки слияния и поглощения осуществляются с меньшими временными и финансовыми затратами. Посредством анализа ретроспективных данных за десятилетие выявлено, что инвесторы готовы получить более низкую премию при выходе из бизнеса посредством сделки слияния и поглощения, нежели нести расходы при осуществлении IPO [15].

При выходе мажоритария из бизнеса посредством сделки слияния и поглощения, миноритарии выигрывают за счёт того, что новый более сильный игрок - мажоритарий обладает большими возможностями формирования стоимости бизнеса и тем самым обеспечит рост благосостояния миноритариев. Вместе с тем сохраняются традиционные риски, связанные со сделками слияния и поглощения, такие как: изменение стратегии развития компании, корпоративной культуры и увольнение предыдущего руководства. Если не предусмотреть оговорки в договоре купли-продажи при осуществлении сделки слияния и поглощения, то для начинающей компании перечисленные выше изменения могут стать фатальными. 
При выходе миноритария подобным образом также может сформироваться стратегическая угроза для бизнеса. При условии, что в рамках сделки слияния и поглощения приобретатель миноритарной доли - основной конкурент целевой компании, то в последующем он получает доступ, в том числе к коммерческой тайне компании, и в момент времени, когда будет принято решение о продаже бизнеса целиком, может оказаться единственным покупателем и приобрести компании по цене, ниже рыночной.

Если же в рамках сделки слияния и поглощения приобретается вся компания, то бывшие инвесторы осуществляют полный выход из бизнеса и получают премию за контроль. Подобный сценарий предпочтителен для начинающих компаний в секторе высоких технологий, полученную премию возможно использовать для развития нового проекта. В последние годы действительно распространена практика приобретения крупными корпорациями начинающих компаний в целях получения технологий и идей, а также возможности привлечь перспективный интеллектуальный капитал в лице создателей бизнеса и разработчиков продукта. При условии создания успешной и перспективной технологии возможно привлечь ряд покупателей и повысить стоимость бизнеса в процессе торгов, тогда первоначальные инвесторы получают более высокую премию, что позволяет одновременно обеспечить определённый уровень благосостояния и деловой репутации.

Если же компания не стала частью иной и успешно зарекомендовала себя в сфере исследований и разработок до процедуры IPO, то инвесторам рекомендуется обращать внимание на показатели, характеризующие исследовательскую деятельность, как критерии отбора компаний в инвестиционный портфель. Поскольку подобные компании проходят IPO успешнее, нежели компании, чья деятельность в сфере высоких технологий стала показывать отличные результаты уже после выхода на фондовую биржу [16]. Выход на фондовую биржу с первым публичным предложением стать акционерами компании является третьим сценарием выхода инвестора из бизнеса. Данный процесс занимает продолжительный период времени и, как уже отмечалось выше, требует существенных затрат. Ввиду этого не так много молодых компаний решается перейти в статус публичных, несмотря на открывающиеся возможности по привлечению дополнительного внешнего финансирования. В случае успешного IPO капитализация компании может повыситься в разы и тогда благосостояние инвестора многократно возрастает.

Тем не менее ряд учёных рассматривает размещение на фондовой бирже как ограничение процесса выхода инвестора из бизнеса, поскольку обычно на период до шести месяцев устанавливается запрет, согласованный с андеррайтерами, в течение которого венчурный инвестор должен сохранить большинство своих акций после IPO [17]. Таким образом, на определённый период времени инвестор теряет возможность выхода из бизнеса и отчасти теряет ликвидность, поскольку долю в бизнесе невозможно в кратчайшие сроки трансформировать в денежные средства.

В целях недопущения срыва процедуры IPO в инвестиционный договор включается такое дополнение, как «demand right», то есть право требования регистрации. Обладающий таким правом инвестор может настоять на превращении компании в публичную. Таким образом, данное право нивелирует возможность сорвать процедуру IPO и тем самым нанести компании существенный репутационный и финансовый урон.

Подобные дополнительные соглашения могут быть привязаны к иным сделкам компании. Существует практика, когда в соглашении прописывается, что акционер или группа акционеров, владеющих более 75\% акций, могут в любой момент времени спустя некий период времени после завершения сделки слияния и поглощения, уведомить иных акционеров о желании трансформировать компанию в публичную [18]. После уведомления руководство компании обязано приложить все усилия для успешной реализации IPO.

Рассмотренные сценарии выхода инвестора из бизнеса, несмотря на возможные дополнительные условия инвестиционного договора, тем не менее оставляют открытым вопрос возможности хеджирования от риска потери контроля над стратегическим развитием компании. На наш взгляд, наиболее эффективным инструментом, позволяющим решить данную задачу, являются мультиголосующие акции. Непредусмотренные российским законодательством, однако распространённые за рубежом, они используются в том числе российскими компаниями, прошедшими листинг на зарубежных биржах. В основном данным инструментом пользуются семейные и высокотехнологичные компании, для которых приверженность установленной стратегии развития является важным элементом обеспечения непрерывной деятельности. 
Мультиголосующая акция - финансовый инструмент, подтверждающий право владельца на долю в компании, на получение части прибыли в виде дивидендов и право участия в управлении множеством голосов, пропорциональных иным долям.

В настоящее время мультиголосующие акции широко распространены в США, особенно среди высокотехнологичных компаний. В Великобритании рассматривается возможность разрешения эмиссии мультиголосующих акций с целью привлечения на лондонскую фондовую биржу большего количества высокотехнологичных компаний. Ключевая характеристика мультиголосующих акций предоставление владельцу пула голосов - при прочих равных условиях позволяет нивелировать влияние иных инвесторов на стратегическое развитие компании. Даже при условии, что основатели компании являются миноритариями, использование мультиголосующих акций позволяет успешно управлять компанией вне зависимости от того, кому продаётся мажоритарная доля. Допуская, что выходящий инвестор обладал мультиголосующими акциями при осуществлении сделки куплипродажи своей доли, он по умолчанию конвертировал их таким образом, что покупатель получает долю без дополнительных голосов. Соответственно, при определении стоимости доли выходящего инвестора, обладающего мультиголосующими акциями, будут применяться традиционные подходы и методы оценки стоимости активов.

Таким образом, стратегия хеджирования от риска потери контроля над стратегическим развитием при выходе инвестора из бизнеса может включать в себя использование дополнительных условий инвестиционного договора, а также такой финансовый инструмент, как мультиголосующие акции.

\section{СПИСОК ЛИТЕРАТУРЫ}

1. Ващенко Т.В., Лисицына Е.В. Поведенческие факторы, влияющие на процесс принятия финансовых решений хозяйствующими субъектами российского рынка // Финансовый менеджмент. 2008. № 2. С. 107-125.

2. Mason C., Harrison R.T., Botelho T. Business angel exits: strategies and processes. In: Research Handbook on Entrepreneurial Finance - Cheltenham: Edward Elgar Publishing Limited, 2015. 288 p.

3. Hart O. Incomplete Contracts and Control // American Economic Review. 2017. № 107 (7). P. 1731-1752.

4. Kaplan S. N., Strömberg P. Financial Contracting Theory Meets the Real World: An Empirical Analysis of Venture Capital Contracts // The Review of Economic Studies. 2003. Vol. 70. №. 2. P. 281-315.

5. Lohwasser T.S. Meta-analyzing the relative performance of venture capital-backed firms // Discussion Papers of the Institute for Organisational Economics. 2020. № 4. URL: https://www.econstor.eu/bitstream/10419/217220/ 1/1698075596.pdf.

6. Bengtsson O., Sensoy B. Changing the Nexus: The Evolution and Renegotiation of Venture Capital Contracts // Journal of Financial and Quantitative Analysis. 2015. № 50 (3). P. 349-375.

7. Félix E.G.S., Pires C.P., Gulamhussen M.A. The exit decision in the European venture capital market // Quantitative Finance. 2014. № 14 (6). P. 1115-1130.

8. Bienz C., Walz U. Venture Capital Exit Rights // Journal of Economics \& Management Strategy. 2010. Vol. 19. № 4. URL: https://papers.ssrn.com/sol3/papers.cfm?abstract_id=1140128.

9. Schwienbacher A. Venture capital investment practices in Europe and the United States // Financial Markets and Portfolio Management. 2008. № 22. P. 195-217.

10. Félix E.G.S., Pires C.P., Gulamhussen M.A. The exit decision in the European venture capital market // Quantitative Finance. 2014. № 14 (6). P. 1115-1130.

11. Янковский Р.М. Правовые средства осуществления венчурных сделок // Предпринимательское право. Приложение «Право и Бизнес». 2017. № 3. С. 42 - 48.

12. Ломакин Д.В. Коммерческие корпорации как субъекты корпоративных правоотношений: учеб. пособие. М.: Статут, 2020. $146 \mathrm{c}$.

13. Warrant holder right agreement. URL: https://www.lawinsider.com/contracts/4Jej8ASaF3ojq3oJmkSnOh/monacocoach-corp-de/warrantholder-rights-agreement/2008-11-13.

14. Pre-Emption Group. URL: https://sway.office.com/HHPgz98MJB2jfEqM.

15. Amora S.B., Koolib M. Do M\&A exits have the same effect on venture capital reputation than IPO exits? // Journal of Banking \& Finance. 2020. Vol. 111. № 2.

16. Chemmanur T. J., Gupta M., Simonyan K. Top Management Team Quality and Innovation in Venture-Backed Private Firms and IPO Market Rewards to Innovative Activity // Entrepreneurship Theory and Practice. 2020. URL: https://www.researchgate.net/publication/340873248.

17. Aghion P., Bolton P., Tirole J. Exit Options in Corporate Finance: Liquidity Versus Incentives // Review of Finance. 2004. № 8 (3). P. 327-353. 
18. Chengdu Tianqi Group Co., Ltd. and Tianqi Group HK Co., Limited Sichuan Tianqi Lithium Industries, Inc. and Tianqi UK Limited RT Lithium Limited Windfield Holdings Pty Ltd Shareholders Agreement. URL: https://www.sec.gov/ Archives/edgar/data/1315695/000110465914036428/a14-9656_1ex10d1.htm.

Поступила в редакцию 11.01.2021

Восканян Роза Оганесовна, кандидат экономических наук, доцент, доцент департамента финансового и инвестиционного менеджмента ФГОБУ ВО «Финансовый университет при Правительстве Российской Федерации» 127083, Россия, г. Москва, ул. Верхняя Масловка, 15

E-mail: rose.01@mail.ru

\section{R.O. Voskanyan \\ SCENARIOS OF THE INVESTOR'S EXIT FROM VENTURE INVESTMENTS}

DOI: $10.35634 / 2412-9593-2021-31-1-5-11$

The subject of research is contractual relationships between the investor and the founders of a young company, which predetermine exit scenarios for the investor at different stages of the company's development.

To identify the main scenarios of the investor's exit from venture capital investments, the author uses research methods such as synthesis and comparative analysis.

Analysis of Russian and foreign scientific literature has revealed that the main focus is on the exit of a venture investor from a business, and insufficient attention is paid to the exit of a business angel. The article considers additional contract terms that are not widespread in Russia, but are used in practice in foreign countries, which regulate the exit of an investor from a business, namely "drag-along", "tag along" and "demand right". The advantages and disadvantages of the main scenarios of the investor's exit from a business for both sides of investment relations are determined.

Based on the results of considering the main scenarios of investor's exit from a business and the key risks characterizing them, the instrument of internal hedging against the risk of a radical change in the company's development strategy due to the change of investor has been determined - multi-voting shares.

Founders and investors can use the results obtained in the study at the early stages of company's development.

Keywords: business angel, venture investor, venture contract, contract theory, investment agreement, minority shareholder, majority shareholder, start-up.

Voskanian R.O., Candidate of Economics, Associate Professor

at Department of financial and investment management

Financial University under the Government of the Russian Federation

Verkhnyaya Maslovka st., 15, Moscow, Russia, 127083

E-mail: rose.01@mail.ru 